\section{Preventing major depression in young people}

\author{
GAVIN ANDREWS, MARIANNA SZABO and JANE BURNS
}

Major depression was the fourth most important determinant of the burden of human disease in 1990 and is expected to rank second in the world by 2020 . It is the principal cause of disability in developed countries and the central question is why the burden of depression is not receding at the same rate as the burdens of infectious and perinatal disorders, which in 1990 were diseases of greater burden. The past 5 years have seen increased recognition that depression is a recurring condition that might best be managed as a chronic disease (Andrews, 2001). We have calculated (Andrews et al, 2000) that some $13 \%$ of the burden of depression is currently being averted. If coverage, clinician competence and compliance were optimal and the health service delivery and financing issues no barrier, we further calculated that only $36 \%$ of the burden could be averted using current interventions and knowledge. Thus, it would appear that $64 \%$ of the burden of major depression cannot be averted. This is a situation in which effective prevention can be critical. In population surveys, one-third of people who have met criteria for major depression in their lifetimes report that the first attack occurred before the age of 21 (Andrews, 2001). Prevention, if it is to be effective, must therefore take place in young people.

Are there programmes whose principal aim is to prevent depression? Two recent reviews of the prevention of mental disorders are optimistic about the field in general (Greenberg et al, 2001; Hosman, 2001), even if they are more guarded about programmes to prevent depression. The systematic review by Gillham et al (2000) on preventing depression is excellent, but still remains cautious. The past year has seen a number of publications where this emphasis has changed. Prevention programmes (called universal programmes) can be applied to the whole population, or targeted towards those with identified risk factors or with early symptoms of a disorder. Offord et al (1998) have discussed the trade-offs, noting that universal interventions are most acceptable but likely to be more costly, while targeted prevention depends on the accuracy of screening programmes that could stigmatise recipients.

\section{UNIVERSAL PROGRAMMES THAT AIMED TO PREVENT DEPRESSION}

Clarke et al (1993) reported on two highschool-based interventions. In the first study, students were randomly assigned to three class lessons covering the symptoms, causes and treatment of depression and were encouraged to use pleasant activities to help prevent the onset or exacerbation of depressive mood. Compared with the control condition, there was some benefit to boys in the short term but this was not sustained over the 12-week follow-up. In the second study, students were randomly assigned to five class lessons on depression, four of which concentrated on skill training related to pleasant-event scheduling. There were no significant differences between the control and intervention groups despite adequate sample sizes. Gillham et al (2000) commented that the interventions in these studies could have been too weak to produce a benefit.

Shochet et al (2001) reported on a cohort study $(n=260)$ implemented within a high-school curriculum. In the first cohort depressive symptoms in year 9 students (aged 14 or 15) were measured on three occasions over 15 months. In the second year, those in the next cohort were similarly measured, but between the first and second measurements they received an 11-session, small group programme, largely modelled on the cognitive therapy approaches of Clarke et al (1995). The programme was led by psychologists and a high level of programme integrity was attained. The student participation rate was $88 \%$. Results were clear: the intervention cohort showed a significant reduction in depressive symptoms that continued unabated at the 10-month follow-up; the control cohort did not. The overall effect size was small, but the authors presented evidence that $13 \%$ of children in the intervention cohort who, on the basis of the control cohort, would have been expected to remain subclinically or clinically depressed, now scored in the healthy range. The 11 hours of therapist time per successful participant seemed more efficient than clinical treatment. They argued for the wider implementation of universal prevention of depression.

Petersen et al (1997) reported on a randomised trial of psychoeducation and problem solving, given by clinical psychologists over 16 class sessions to children aged 11-14 years, to increase their ability to cope with stress and decrease the development of depressive symptoms. There were no intervention effects on depressive symptoms post-trial or at 12month follow-up.

Spence et al (2002) randomly assigned high schools ( $n=1500$ students) to receive a teacher-delivered, 8-session, pedagogically sophisticated programme to improve problem-solving orientation and, to a lesser extent, to reduce negative cognitive bias. Compared with students in the control classes who received no such tuition, depressive symptoms declined significantly by the end of the programme. At the 12month follow-up, high-risk students retained their improved problem-solving orientation but the overall benefit to depressive symptoms was no longer evident. This was a large, carefully run study with the power to detect clinically significant differences. The differences between the Spence and the Shochet studies was that the latter used psychologists not teachers, small groups not whole classes, and emphasised cognitive therapy not problem solving. Even so, the attenuation of the observed benefit in Spence et al's more powerful study is disappointing.

\section{TARGETED PREVENTION PROGRAMMES}

Children whose parents suffer from depression are at heightened risk of developing depression themselves and the explanation is likely to be more psychological than genetic (Beardslee et al, 1998). Beardslee 
et al (1997) reported on a randomised controlled trial where parents and children were given a 6 - to 10 -session clinician intervention or a 2 -session lecture discussion. Results after 36 families had been randomised showed increased satisfaction and understanding in the intervention group but no difference in child depression scores.

Clarke and Beardslee (Clarke et al, 2001) took a similar group. They identified parents with a history of depression and targeted their adolescent children, aged 13-18, who had depression symptoms insufficient to meet DSM-III-R criteria (American Psychiatric Association, 1987) for an affective disorder $(n=94)$. They randomly assigned these adolescents to usual care, or to a 15 -session, small group cognitive therapy programme conducted by therapists with a master's degree. The treatment manual is available at http:// www.kpchr.org/acwd/acwd.html. After a median 15-month follow-up, the incidence of major depression in the intervention group was one-third that in the control group $(9.3 \%$ v. $28.8 \%)$ - an impressive result.

Clarke et al (1995) had achieved a similar result in 150 adolescents with symptoms of depression who, on interview, failed to meet the diagnostic criteria for major depression or dysthymia. Using the same 15session cognitive therapy programme, they found that after 12 months, the incidence of major depression in the intervention group was half that in the control group $(14.5 \%$ v. $25.7 \%)$. Using the same calculations as Shochet et al (2001), one would presume that prevention was cheaper than waiting for these adolescents to develop into cases and then treating them.

There is evidence that a negative attributional style is a risk factor for depression (Gillham et al, 1995; Gillham \& Reivich, 1999). Gillham and colleagues identified 118 fifth- and sixth-grade children (aged 10-11 and 11-12 years, respectively) at risk for depression and, using a matched cohort design, applied variants of the Penn Optimism Program in 12 after-school group sessions each lasting 2 hours. The programme emphasised cognitive therapy but included elements of social problemsolving, relaxation and assertiveness. Children in the intervention group reported significantly fewer symptoms of depression over the next 2 years, and the levels of moderate and severe symptoms were halved in the intervention group. No significant differences in depression remained by the end of the third year, but the drop-out rate had increased to $43 \%$ and only small numbers of children remained in the study. The prevention groups did show a sustained improvement in negative explanatory style, one of the hypotheses being tested.

Seligman et al (1999) identified the quarter of university freshmen who had the most pessimistic explanatory styles and randomly allocated them to eight 2-hour sessions that emphasised cognitive therapy $v$. no intervention. A prevention effect was found for self-reported depression and anxiety symptoms, but the effect did not extend to severe levels of depression.

\section{COMMENT}

There are nine studies that bear on the question, 'Can depression in young people be prevented?' Clarke et al (1993) used teachers in the classroom to deliver brief psychoeducation and found no benefit. Petersen et al (1997) used psychologists and Spence $e t$ al (in press) used teachers in classroom situations to deliver extensive psychoeducation and problem solving and found no benefit. Knowing what does not work is as important as knowing what does work and both Petersen and Spence appear to have struggled to get their negative results published. Beardslee et al (1997) gave clinician-assisted advice to a target group with no resulting benefit over brief information sessions and his negative result was published, presumably because of interest in the plight of children of parents with depression. The remaining five studies used variants of cognitive therapy or cognitive-behavioural therapy delivered by psychologists and showed benefit, sometimes confined to symptoms but sometimes extending to a reduced incidence of major depressive disorder. The problem is not efficacy - the Clarke et al (1995) cognitive therapy programme works - but effectiveness in routine practice. There simply are not enough psychologists in any country who are trained to deliver cognitive therapy and can be deployed into the school system to conduct either universal or targeted prevention programmes.

There is no evidence that recent initiatives are reducing the prevalence of depression and there is evidence that cognitive strategies are available which can reduce its incidence. It is not simply a matter of preventing major depressive disorder in high-risk groups. If we adopt the public health approach and move the distribution of depressive symptoms in the population by a small amount, we will get a corresponding reduction in the number of overall cases of major depression. The problem is delivery. Clarke and ourselves (and presumably many others) are exploring the use of computer-based interactive programs in schools, backed by guided access to resources on the internet. The problem is too important to be restricted to the traditional method of face-to-face intervention, but knowing that cognitive therapy is a cost-effective method of preventing depression in high-risk groups is a considerable advance.

\section{REFERENCES}

American Psychiatric Association (1987) Diagnostic and Statistical Manual of Mental Disorders (3rd edn, revised) (DSM-III-R). Washington, DC: APA.

Andrews, G. (200I) Should depression be managed as a chronic disease? BMJ, 322, 419-42I.

_ , Sanderson, K., Corry, J., et al (2000) Using epidemiological data to model efficiency in reducing the burden of depression. Journal of Mental Health Policy and Economics, 3, 175-186.

Beardslee, W. R., Wright, E. J., Salt, P., et al (1997) Examination of children's responses to two preventive strategies over time. Journal of the American Academy of Child and Adolescent Psychiatry, 36, 196-204.

_, Versage, E. M. \& Gladstone, T. R. G. (1998)

Children of affectively ill parents: a review of the past 10 years. Journal of the American Academy of Child and Adolescent Psychiatry, 37, |134-1141.

Clarke, G. N., Hawkins, W., Murphy, M., et al (1993) School-based prevention of depressive symptomatology in adolescents. Journal of Adolescent Research, 8, 183-204.

_ , _ , _ , et al (1995) Targeted prevention of unipolar depressive disorder in an at-risk sample of high school students. Journal of the American Academy of Child and Adolescent Psychiatry, 34, 312-321.

_ , Hornbrook, M., Lynch, F., et al (200I) A randomized trial of group cognitive intervention for preventing depression in adolescent offspring of depressed parents. Archives of General Psychiatry, 58, II27-II34.

Gillham, J. E. \& Reivich, K. J. (1999) Prevention of depression in schoolchildren. Psychological Science, 10, 46I-462.

_ , _ , Jaycox, L. H., et al (1995) Prevention of depressive symptoms in schoolchildren. Psychological Science, 6, 343-351.

_ , Shatte, A. J. \& Freres, D. P. (2000) Preventing depression: a review of cognitive behavioral and family interventions. Applied and Preventive Psychology, 9, 63-88.

Greenberg, M. T., Domitrovitch, C. \& Bumbarger, B.

(200I) The prevention of mental disorders

in school-aged children: current state of the field. Prevention and Treatment, 4, article I (http: // www.journals.apa.org/prevention/volume4/ pre004000la.html). 
Hosman, C. M. H. (200I) Evidence of effectiveness in mental health promotion. In Proceedings of the European Conference on Promotion of Mental Health and Social Inclusion (eds J. Lavikainen, E. Lahtinen \& V. Lehtinen). Helsinki: Edita.

Offord, D. R., Kraemer, H. C., Kazdin, A. E., et al (1998) Lowering the burden of suffering from child psychiatric disorder: trade-offs among clinical, targeted, and universal interventions. Journal of the American Academy of Child and Adolescent Psychiatry, 37, 686-694.

Petersen, A. C., Leffert, N., Graham, B., et al (1997)

Promoting mental health during the transition into adolescence. In Health Risks and Developmental

Transitions during Adolescence (eds J. Schulenberg, J. L.

Maggs \& A. K. Hierrelmann). New York: Cambridge

University Press.

Seligman, M. E. P., Schulman, B. S., DeRubeis, R. J., et al (1999) The prevention of depression and anxiety.

GAVIN ANDREWS, FRCPsych, MARIANNA SZABO, PhD, Clinical Research Unit for Anxiety and Depression, University of New South Wales at St Vincent's Hospital, Sydney, Australia; JANE BURNS, PhD, beyondblue, The National Depression Initiative, Melbourne, Australia

Correspondence: Gavin Andrews, 299 Forbes Street, Darlinghurst, NSW, Australia, 2010. E-mail: gavina@crufad.unsw.edu.au

(First received 3 January 2002, final revision 7 May 2002, accepted 15 May 2002)

Prevention and Treatment, 2, article 2 (http: // www.journals.apa.org/prevention/volume2/ pre0020008a.html).

Shochet, I. M., Dadds, M. R., Holland, D., et al (200I) The efficacy of a universal school-based program to prevent adolescent depression. Journal of Clinical Child Psychology, 30, 303-315.

Spence, S. H., Sheffield, J. \& Donovan, C. L. (2002) Preventing adolescent depression. Journal of Consulting and Clinical Psychology, in press. 